Article

\title{
Determinants of Plate Leftovers in One German Catering Company
}

\author{
Bettina A. Lorenz ${ }^{1,2}$, Monika Hartmann ${ }^{2}$, Stefan Hirsch ${ }^{3}$, Olga Kanz ${ }^{2}$ and Nina Langen ${ }^{1, *}$ \\ 1 Department of Education for Sustainable Nutrition and Food Science, Institute of Vocational Education and \\ Work Studies, Technische Universität Berlin, Marchstraße 23, 10587 Berlin, Germany \\ 2 Department of Agricultural and Food Market Research, Institute for Food and Resource Economics, \\ University of Bonn, Nussallee 21, 53115 Bonn, Germany \\ 3 ETH Zürich, Agricultural Economics and Policy Group, Sonneggstrasse 33, 8092 Zürich, Switzerland \\ * Correspondence: nina.langen@tu-berlin.de; Tel.: +49-030-314-73366
}

Academic Editor: Zenon Foltynowicz

Received: 27 February 2017; Accepted: 3 May 2017; Published: 12 May 2017

\begin{abstract}
Since the majority of food waste in high-income countries occurs at the consumption stage and given the clear trend towards out-of-home food consumption, it is important to understand the factors that lead to food waste in the hospitality sector. The present study uses a behavioral structural equation model to test the drivers of consumers' leftover behavior in an out-of-home setting. Based on the Theory of Planned Behavior, we additionally consider "personal norms" and the situational "taste perception" of food as determinants. Our results in a company canteen demonstrate that personal norms and attitudes greatly determine consumers' intention to prevent leftovers, whereas subjective norms and perceived behavioral control appear less relevant. Stated leftover behavior depends on both behavioral intention and the situational taste perception of food. We show that in order to understand individual food leftover behavior in an out-of-home setting, determinants from behavioral theories should be complemented by situational variables.
\end{abstract}

Keywords: food waste; leftovers; hospitality sector; consumer survey; behavioral structural equation model

\section{Introduction}

Food waste has become a focal point of interest in media, politics, research and business. Globally, 1.3 billion tons of food produced for human consumption are wasted each year. The fact that overall around $30-50 \%$ of produced food ends up uneaten as waste [1] demonstrates that scarce resources are inefficiently allocated. The food systems' impact on natural resources such as water, land and climate, as well as on ecosystems, is undeniable (see e.g., [2-5]). For example, 70\% of fresh water use worldwide can be attributed to the food system [5]. Goebel et al. [6] analyze four exemplary supply chains and highlight that food waste arises at all levels of the food value chain resulting in a need to share responsibility and cooperate to reduce food waste. Halloran et al. [7] also stress that food supply network structures influence food waste through their interrelated decision making giving food waste a dynamic flow characteristic. It is estimated that European consumers waste about $95 \mathrm{~kg}$ food per capita annually [1]. Most of this waste has been stated to stem from food consumption at home [8]. Stenmarck et al. [9] investigate food waste along the supply chain and also consider available household data from 2012 reported by 11 out of 28 European member states. They found that food waste ranges from 44 to $130 \mathrm{~kg} /$ person/year with a mean of 71 and a median of $67 \mathrm{~kg} /$ person/year. This variance makes obvious that statements about one actor's particular responsibility should be taken carefully since reliable data concerning the amount of food waste on different stages in the food value chain are lacking in many countries $[7,10]$. As long as some actors (e.g., farms and retailers) do 
not measure/publish their findings research, research concentrates on those willing to give insights into their behavior and motivations. Accordingly, different studies have measured and evaluated the creation of avoidable food waste at home. Thereby, it has become obvious that food waste is subject to a wide set of behaviors, routines, skills, values and norms related to social structures between persons within and outside a household as well as to lifestyle [11-14]. Specific behaviors and routines that have been addressed with respect to food waste reach from recommendations for food shopping routines [15] and thus the provision of action knowledge over education for food-related knowledge [16] to social network approaches for avoiding losses [17] and social media interventions by retailers [18].

However, with regards to the increasing importance of out-of-home food consumption, i.e., in restaurants, canteens or kiosks (e.g., [19]) or schools [20], there is a need to "link good consumer behaviors $(\ldots)$ in the home with those that occur when eating out" for future reductions of food waste [21]. In this context, it should be noted that out-of-home settings in different countries, although to a lower extent than private households, have been found to add a relevant share of total food waste $[2,22,23]$, thus are a relevant field of action to reduce negative environmental effects of food consumption [24]. Falasconi et al. [20] could show that a significant driver of food waste in schools is the amount of food processed but not served. Food waste in catering facilities can be regarded as a loss of resources and hence should be reduced as much as economically feasible. However, it could also be that reducing food waste requires disproportionally high efforts resulting in high input of labor or time [6]. Independent of this, at the level of guests, a low share of leftovers have been described as potential indicator of consumer satisfaction, i.e., assuming "good" satisfaction being related to a ratio of less than 1:10 between food waste and food consumption [25]. In line with this perspective, consumer food waste in food services relates to aspects such as menu offerings [25,26], portion sizes [27] or serving styles [28]. Complementary, various studies on food-related behaviors of consumers in out-of-home settings indicate the relevance of personal factors, such as attitudes and subjective norms for the choice of healthier food offerings [29], or knowledge and problem awareness for the reduction of food waste in a self-service setting [30]. Hence, it may well be assumed that food waste originating from guests in the hospitality sector may depend on both service related aspects and personal factors.

Our paper contributes to this still small but emerging research stream by providing a more holistic understanding of consumer food waste behavior in an out-of-home setting, more specifically in a company canteen. With more than 11 billion visitors in 2015 and around 30 million guests per day in Germany [31], the out of home catering sector has considerable influence on nutritional status and behavior of different people. Given its regular nature, food consumption in company canteens bears a great potential to reduce food waste in this specific setting and to shape food habits even beyond it [32,33].

The objective of our study is to derive insights into customers' wasting behavior in canteens and thus their decision to consume or leave behind food they ordered, and the factors influencing this process. By this, an understanding is provided to the relevance of personal and service-related environmental factors in determining leftover behavior. Consumer food leftover behavior in canteens is modeled by an extension of the Theory of Planned Behavior (TPB). Besides the classical constructs of the TPB, additional behavioral determinants with relevance for waste behavior in other settings (private households) and for sustainable food consumption behaviors out-of-home are included in the model. Moreover, we add perceived taste as situational variable and classical factor of food waste to our model. The results of the study enable the hospitality sector to reduce guests' leftovers.

In the course of the paper we first present our research hypotheses and relate them to our theoretical framework (Section 2). This is followed by sections that describe the study design (Section 3) and findings including the sample properties (Section 4). Finally, the results and limitations are discussed (Section 5) and conclusions are derived (Section 6). 


\section{Derivation of Research Hypotheses}

Generally, the TPB is a behavioral model that has extensively been applied for individual health and food related behaviors [29,34-38]. It states that behavior can be determined by measuring behavioral intention [39]. Behavioral intention itself is influenced by three constructs: first by attitudes towards the behavior; second by perceived social norms (subjective norms) or the evaluation of relevant others with respect to the behavior; and third by perceived behavioral control over the behavior [39,40]. In line with past research on food and waste related consumer behavior, four hypotheses were derived for leftover behavior of canteen guests.

First, the classical TPB was addressed in formulating two hypotheses (H1 and H2) for a basic behavioral model:

Hypothesis 1 (H1). The amount of individual plate leftovers on a specific day is negatively determined by the behavioral intention to eat food served on the tray completely.

Hypothesis 1 refers to the relationship between intended and actual behavior. A review of 167 studies that were based on the TPB supports this relationship [41]. On average, intention explained $31 \%$ of the variance in self-reported and $20 \%$ of the variance in observed behaviors. More specifically, Tarkainen and Sundqvist [42] found a significant positive relationship between the intention to buy organic food and stated frequency of buying organic food. Mahon et al. [43] reveal a similar relationship for the intention to and stated purchase of ready meals and takeaway. Furthermore, Harland et al. [44] were able to relate different pro-environmental behaviors (i.e., reduced meat consumption or using other transport forms than car) to the respective behavioral intentions.

Hypothesis 2 (H2). The behavioral intention to eat food served completely is positively determined by:

(a) negative attitudes towards food leftovers;

(b) subjective norms against the disposal of food; and

(c) perceived behavioral control of eating everything up.

Hypothesis 2 relates to the relationship between the TPB constructs attitudes, subjective norms and perceived behavioral control as well as the intention to pursue a behavior, and has been intensively investigated in the literature (see, e.g., review article by Armitage and Connor [41]). Exemplarily, the significant influence of attitudes, subjective norms and perceived behavioral control were empirically supported for general sustainable food consumption intentions [45], to the intention not to purchase genetically modified food products [46] as well as to recycling intents [47].

Second, in addition to the classical TPB, the behavioral determinant personal norms was included in the model (H3). This extension is theoretically based on the norm-activation theory by Schwartz [48] and has been empirically supported by general correlation findings (independent of TPB constructs) between personal norms and different environmental behaviors for different cultural backgrounds [49]. The construct personal norms measures a normative evaluation of the behavior based on personal value systems. Previous studies revealed that the extension of the TPB by this construct increased the explained variation in behavioral intentions for sustainable consumer behaviors such as organic food purchasing [50] as well as household waste recycling [51,52]. Moreover personal norms have been found to be interrelated with subjective norms $[50,53]$.

Hypothesis 3 (H3). Personal norms not to leave food served are a positive determinant of behavioral intention to eat the food served on the tray completely and, as a consequence, negative attitudes towards food leftovers.

Though the TPB suggests that, if all relevant behavioral determinants are measured sufficiently, external factors should not have an independent influence on the analyzed behavior, recent studies suggest situational factors to be of relevance [54]. In line with this, Aertsens et al. [53] extended the 
TPB by situational factors for modeling organic food purchasing at one specific time point. Along the same lines, Tonglet et al. [55] found that the inclusion of the situational factors time and space significantly improved the explained variance in household' recycling intentions. Since different exploratory studies on food consumption in out of home settings have highlighted the relevance of taste for eating behavior and food leftovers, we decided to include taste as a relevant situational determinant of plate leftovers $[56,57]$.

Hypothesis 4 (H4). The amount of individual plate leftovers on a specific day is negatively influenced by the perceived taste of food on this day.

Accordingly, our structural research model composes of five latent (intention, attitudes, subjective norms, personal norms, and perceived behavioral control) and two directly measured variables (plate leftovers and taste perception) (see Figure 1).

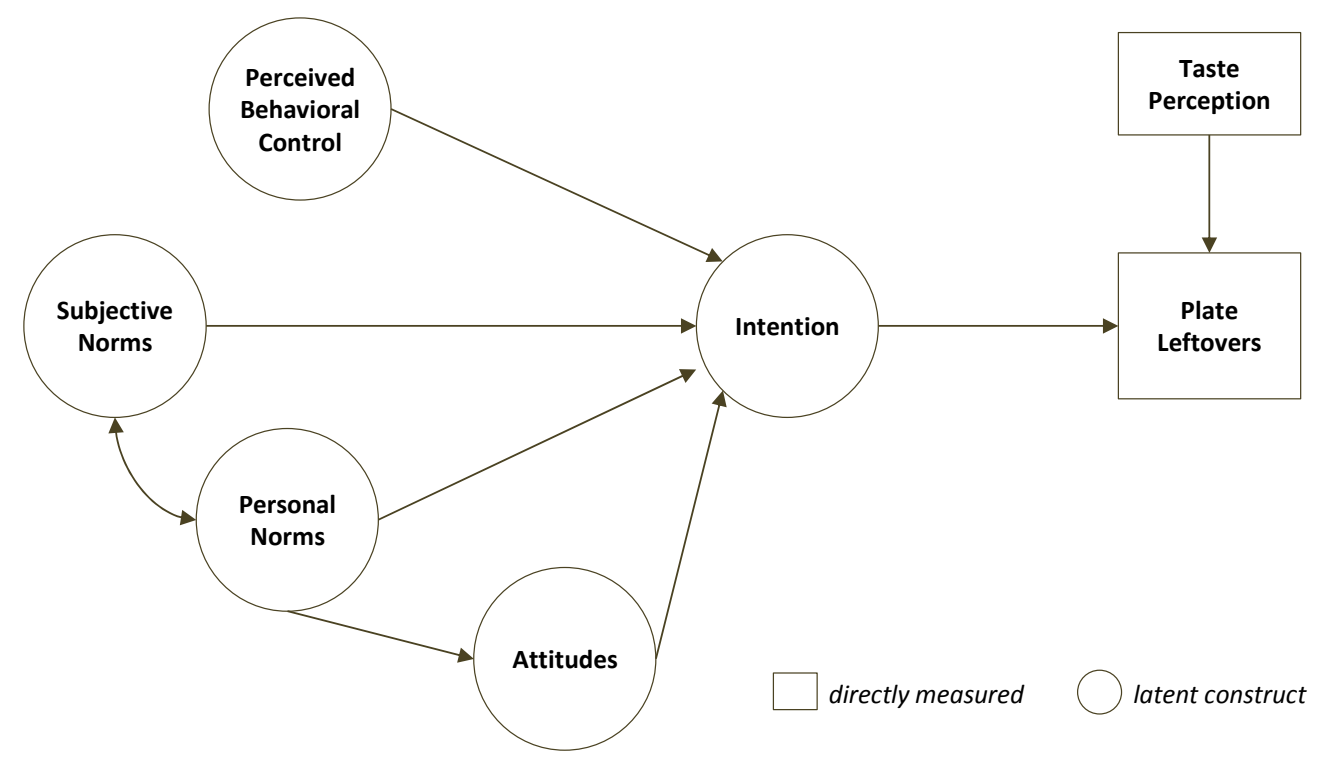

Figure 1. Structural Model.

\section{Methods}

\subsection{Empirical Data}

To test the derived theoretical model, a dataset collected during one week in fall 2012 at a company canteen located in the city of Cologne, Germany, was applied. Overall, 184 guests were recruited to fill out a pen and paper questionnaire comprising three parts: first, general questions referring to the perception of the canteen and environmental issues; second, questions with respect to food leftovers in the canteen, including the presented indicators of the research model; and third, socio-demographic questions. Overall, 130 indicators and 13 complementary demographic variables were measured. Moreover, a qualitative pre-study with $n=30$ respondents regularly eating in company canteens (nine employees of the company in which the final data were collected but working at a different site, 15 civil servants of a Cologne authority, and six students) was available for this data collection. In the pre-study, six open questions were posed in a written questionnaire asking about the drawbacks and negative consequences as well as the advantages and positive consequences of not finishing a dish, whether there is an influence of people or institutions to finish the plate and if yes how this is influencing personal behavior, whether it is difficult to not have leftovers and if yes why, whether there are situations/circumstances that provoke not clearing one's plate, and what can be a motivation not to throw away food. Key results are: the most significant relevant others influencing throw away 
behavior were parents, media, and grandparents. Respondents mentioned feelings of guilt when not clearing their plate but also stood up for the right to prioritize the individual welfare and to have leftovers instead of finishing the plate against personal feelings of hunger. Besides, participants did not explicitly address the ecological dimension of food waste but focused on social and economic aspects. Therefore, environmental consciousness has to be induced explicitly in the study. The insights could be applied in order to enrich the findings from the literature review to specify the choice of variables from the dataset according to their stated relevance within the specific canteen setting.

\subsection{Measurement of Behavioral Constructs}

The two situational model components (plate leftovers and taste perception) were measured directly. Regarding the former, respondents were asked to indicate whether when returning the tray on the day of participation they left any of the following meal components on their plate: meat, vegetables, starchy side dishes, salad and dessert. Based on the five answers, an index of the number of leftover meal components was summated, reaching from 0 (no leftovers) to 5 (leftovers of all possible meal components). Perception of taste was measured on a seven-point bipolar scale reaching from very bad to very good.

For four of the five latent constructs (intention, attitudes, subjective and personal norms) and reflective indicator systems were set up (see Table 1). Based on past empirical studies, theoretical literature as well as a qualitative study conducted prior to the data collection ([58] with 30 canteen guests, general measurements of the constructs were adjusted to the specific setting in a canteen. Derived indicators were measured either on seven-point bipolar or on seven-point-Likert Scales. For the fifth construct, perceived behavioral control, preliminary data analysis indicated major issues regarding the consistent correlation of the theoretically suggested indicators [39,59] (it is difficult not to waste any food/wasting food is unavoidable/I can avoid food leftovers if I want to). Moreover, a descriptive analysis of this construct revealed a high perception of behavioral control with little variance among respondents and hence a low relevance of perceived control for the behavioral intention [39]. Therefore, it was decided to dismiss these indicators from the subsequent modeling. Instead, a set of 13 variables were integrated into the model. Those variables covered reasons for food leftovers which were mentioned most frequently in the qualitative pre-study [58] and have also been found relevant in other studies [60]. In the questionnaire, consumers were asked about the frequency of a specific reason for food leftovers on a five-point Likert Scale from "very rarely" to "very frequently". Based on an exploratory factor analysis, the 13 variables were assigned to four standardized (z-scores) unweighted indices (see Table 1). It was assumed that a higher indicated frequency of external reasons leading to plate leftovers represents a lower perceived personal control over the behavior (in line with the H2c).

Table 1. Measurement Systems for Latent Constructs and Indices.

\begin{tabular}{lll}
\hline Latent Construct (Measurement) & \multicolumn{1}{c}{ Indicators } & References \\
\hline Intention (Likert Scale) & $\begin{array}{l}\text { Two indicators: (1) I generally try to return an empty } \\
\text { plate; (2) I generally try not to waste any food in } \\
\text { the canteen }\end{array}$ & {$[39,59]$} \\
\hline Attitudes (7 point bipolar scales) & $\begin{array}{l}\text { Four indicators: Not eating everything up is } \\
\text { (1) right/wrong; (2) appropriate/inappropriate; } \\
\text { (3) acceptable/inacceptable; } \\
\text { (4) responsible/irresponsible }\end{array}$ & [59] \\
\hline Subjective Norms (Likert Scale) & $\begin{array}{l}\text { Two indicators: people that are relevant to me (1) think } \\
\text { that you should not dispose of any food; (2) approve of } \\
\text { me not disposing any food }\end{array}$ & [37] \\
\hline Personal Norms (Likert Scale) & $\begin{array}{l}\text { Three indicators: (1) I think you should not dispose any } \\
\text { edible food; (2) to dispose food is wrong; (3) everyone } \\
\text { should feel responsible not to waste food }\end{array}$ & [37,61] \\
\hline
\end{tabular}


Table 1. Cont.

\begin{tabular}{|c|c|c|}
\hline Latent Construct (Measurement) & Indicators & References \\
\hline $\begin{array}{l}\text { Index 1: Food related reasons } \\
\text { (Likert Scale) }\end{array}$ & $\begin{array}{l}\text { Frequency of five food-related reasons for leftovers: } \\
\text { appearance/temperature/smell/fat } \\
\text { content/texture of food }\end{array}$ & \multirow{4}{*}{ Qualitative pre-study $[58,60]$} \\
\hline $\begin{array}{l}\text { Index 2: Person related reasons } \\
\text { (Likert Scale) }\end{array}$ & $\begin{array}{l}\text { Frequency of three person-related reasons for leftovers: } \\
\text { time pressure/stress/feeling unwell }\end{array}$ & \\
\hline $\begin{array}{l}\text { Index 3: Portion size related } \\
\text { reasons (Likert Scale) }\end{array}$ & $\begin{array}{l}\text { Frequency of three portion-size related reasons for food } \\
\text { leftovers: too much food (self-served)/too much food } \\
\text { (served)/not hungry }\end{array}$ & \\
\hline $\begin{array}{l}\text { Index 4: Taste related reasons } \\
\text { (Likert Scale) }\end{array}$ & $\begin{array}{l}\text { Frequency of two taste-related reasons for food leftovers: } \\
\text { taste of food/dislike of specific ingredients }\end{array}$ & \\
\hline
\end{tabular}

\subsection{Model Estimation}

The analysis of descriptive properties and correlation structure between measured variables (see Appendix A: Tables A1 and A2), apart from moderate skewness $(<2)$ and kurtosis $(<7)$ in most variables, did not indicate major shortcomings with respect to the application of data for further analysis. For model estimation, Full Information Maximum Likelihood (FIML) estimation was applied using the software Mplus. Although the condition of normal distribution for measured variables was violated, complementary estimation via distribution-free Generalized Least Squares under mean-imputation for missing values indicated comparable estimation results regarding overall model fit, factor loadings and regression weights (for a more detailed discussion on the application of FIML estimation, see [62]). Accordingly, it was decided to apply FIML due to the usage of a higher share of data provided by the dataset.

\section{Results}

\subsection{Sample Properties}

Due to high number of missing values for questions relevant for the latent measurement system, 28 cases of the 184 participants were eliminated from the subsequent analysis, resulting in a sample of $N=156$. Since there are no reliable data on typical visitors of company catering in Germany, we compared our sample to the overall German population. In this respect, our sample was biased towards male respondents ( $63 \%$ of sample against $49 \%$ in German population, [63]) and towards people between 26 and 45 years of age (65\% of sample against $42 \%$ in German population, [63]). The latter is not surprising given that the place of data collection was a company catering business. Moreover, the majority of respondents indicated to hold a university degree (63\%) leading to an educational bias of our sample (in Germany 13\% of population hold a university degree; [63]). Regarding household size and monthly income, respondents were considered comparable to the overall German population: most participants (39\%) lived in a two-person household, whereas $26 \%$ of participants lived alone and $35 \%$ indicated a household-size with three or more persons. Households' monthly net income most often was estimated between EUR 2000 to EUR 3000 (47\%). Thirty-one percent stated a lower and 22\% a higher income.

Regarding the general perception of the canteen and environmental issues, the participants indicated a high satisfaction with the company canteen with half of the sample rating the canteen with a 5 or higher on a seven-point semantic differential scale from $1=$ very bad to $7=$ very good. This was also reflected in good ratings for single catering aspects such as the atmosphere and interior design, the service and the food assortment. With respect to the perception of environmental issues, a nine-item scale based on Diekmann and Preisendörfer [64] was applied and indicated a general concern of participants for environmental issues. For all but one item, support for environmentally concerned statements such as "The great majority of German people do not act in an environmentally responsible way" was high with means above 4.5 on a seven-point Likert Scale ( $1=$ strongly disagree, 
7 = strongly agree). The only exception was the item "Environmental protection measures should be carried out, even if this reduces the number of jobs in the economy" with a mean support of 3.99.

\subsection{Plate Leftovers}

Among the sample of 156 canteen guests, 112 (72\%) indicated that they had no food leftovers on the day of their survey participation. The remaining 44 guests stated to have left one (17\%), two (8\%) or three (3\%) food components on the plate (a typical meal of the sample composed of three different food components). In the case of one food component, this mostly referred to leftovers of starchy or vegetable side dishes. Against this, meat in general was stated as leftover when there was more than one food component left on the plate, indicating that canteen guests tend to avoid food leftovers of meat in comparison to starchy and vegetable side dishes.

\subsection{Measurement Systems}

Conducting a Confirmatory Factor Analysis for the four latent constructs, all indicator loadings are highly significant $\left(* * *\right.$ highly significant $(\alpha<0.01),{ }^{* *}$ significant $(\alpha<0.05),{ }^{*}$ moderately significant $(\alpha<0.10))$ and, except for the indicator "I usually try to empty my plate completely in the canteen" in the behavioral intention construct and the indicator "It is wrong to waste food" in the personal norms construct, above the required level of 0.7 [65]; see Table A3). Since the Average Variance Extracted (AVE) is above 0.5 for all measurement systems, these local shortcomings were accepted. Moreover, all measurement systems show sufficient $(>0.7)$ composite reliability based on the estimated factor loadings (see Table A3) and, hence, convergent validity is assumed. Regarding discriminant validity, the Fornell-Larcker Criterion was computed and revealed sufficient differentiation between the four measurement systems [66]; see Table A3).

\subsection{Structural Model}

Estimation of the structural model relationships between the four latent constructs, the two situational variables and the indices reveals a good overall fit to the data with an adjusted Chi-Square minimal discrepancy CMIN $/ \mathrm{df}=(142.17 / 108)=1.27$. This is also supported by the comparative fit index CFI $=0.96$ and Tucker-Lewis Index TLI $=0.95$ as well as a sufficiently low Rooted-Mean-Square-Error of Approximation (RMSEA = 0.042) (for reference see [65,67]. Moreover, modification indices were considered with values greater than 3.84 (a cutoff level of 3.84 may be applied under consideration of significant improvements in the model's Chi-Square value by freeing the respective parameter [65]) (see Table A4). Since none of the modification indices were outstandingly high and since there were no relationships suggested by those indices that were theoretically sound, it was presumed reasonable to keep the final structural model with its restrictions.

With regards to the research hypotheses, H1 (behavioral intention not to leave food on leftover behavior) is supported by the model estimates with a significant negative regression coefficient of 0.235 (see Figure 2). The second hypothesis H2 (TPB determinants of behavioral intention) is backed for the construct attitudes (with a highly significant positive standardized regression weight of 0.251 on intention). Subjective norms are estimated with comparably lower impact of 0.163 and only at moderate significance level (see Figure 2). The influence of perceived behavioral control, measured by the four indices, on behavioral intention is not confirmed. Considering the extension of the classical TPB by personal norms (H3), our estimation strongly supports all suggested relationships with highly significant positive estimates for regression coefficients of 0.339 for attitudes and 0.496 for behavioral intention and a correlation with subjective norms of 0.184, the latter at significance level $\alpha=0.05$. Finally, $\mathbf{H} 4$ (impact of situational perception of taste) is supported with taste having the greatest direct impact (-0.328) on leftover behavior in our estimation (see Figure 2).

Overall, the estimated model reaches highly significant squared multiple correlations (R-squared) for the behavioral intention to prevent plate leftovers in the canteen of 0.488 and for the actual plate leftover behavior on a specific day of 0.162 . Reviewing direct, indirect and total effects within the 
model, personal norms gain additional relevance by their indirect effect on intention via attitudes (indirect effect $=0.085$; total effect $=0.581$ ).

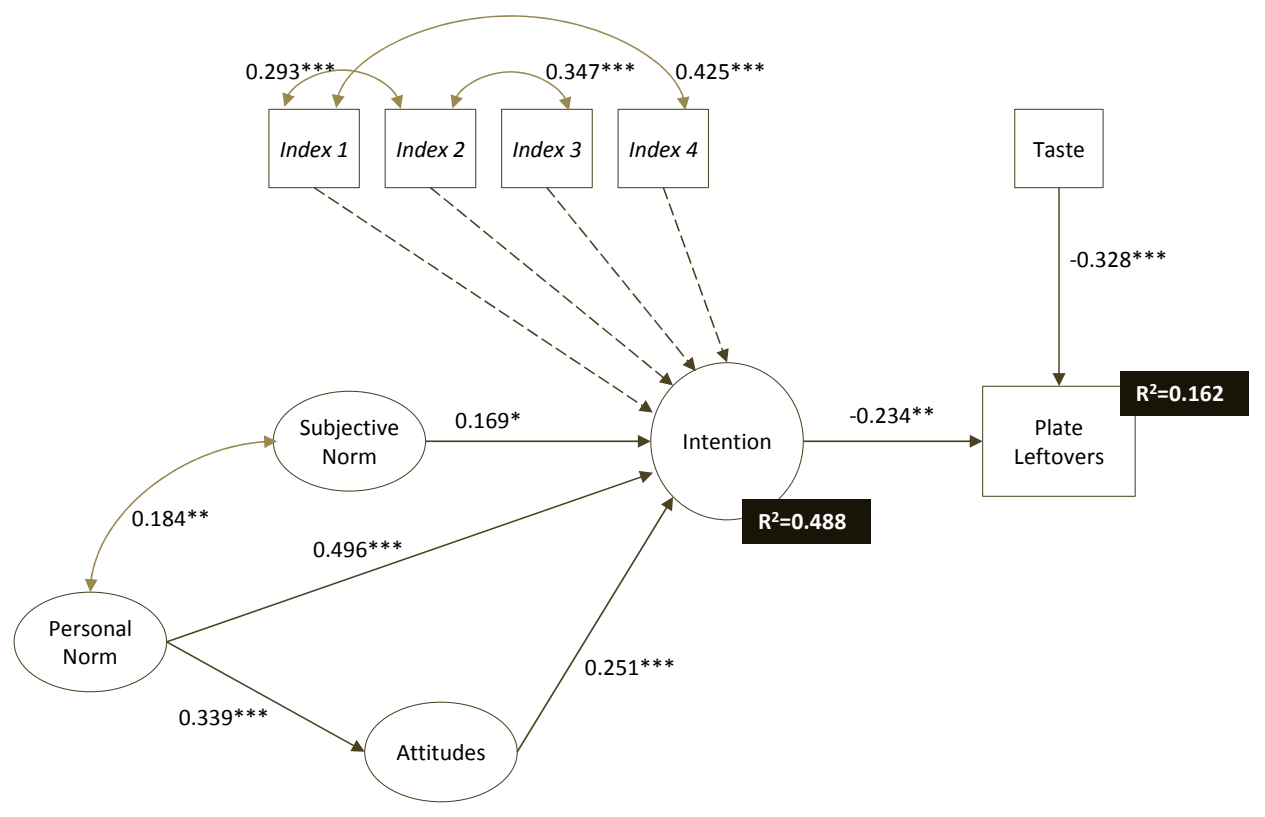

Figure 2. Standardized Estimation Results (only significant). Based on FIML Estimation for $N=156$, significance level $\alpha<{ }^{*} 0.10 ;{ }^{* *} 0.05 ;{ }^{* *} 0.01$.

With respect to the indirect effect of different constructs on the actual leftover behavior, personal norms reach the highest impact, followed by attitudes (see Table 2). In line with their impact on behavioral intention, subjective norms in contrast do not have a significant impact on plate leftovers.

Table 2. Standardized Indirect Effects of Latent Behavioral Constructs on Plate Leftovers.

\begin{tabular}{cccc}
\hline Standardized Indirect Effects & Attitudes & Personal Norm & Subjective Norm \\
\hline Plate Leftovers & $-0.059^{* *}$ & $-0.136^{*}$ & -0.027 \\
\hline
\end{tabular}

Significance level $\alpha<{ }^{*} 0.10 ;{ }^{* *} 0.05 ; * * * 0.01$.

Multiple-group analyses to review the influence of demographic variables on the model were not feasible due to the limited sample size. However, none of the demographic variables significantly determined behavioral intention or plate leftover behavior. This insignificance was found for different levels of environmental concern and satisfaction with the company canteen accordingly. Environmental concern, however, appears to be strongly correlated with personal norms.

\section{Discussion of Findings and Limitations}

Our findings imply that individual plate leftovers in canteens are determined to a relevant extent by behavioral intention to eat the food served. Thereby, this study complements past findings of a successful application of the TPB for pro-environmental behaviors [44], sustainable behaviors such as household waste recycling [37], and food-related behaviors such as takeaway consumption [43] or organic food purchasing [50]. It appears that for behavioral intention to eat food completely and leftover behavior, respectively, the construct of subjective norms is less relevant than attitudes and personal norms. This result is in line with a study by Mahon et al. [43] on ready meal and takeaway consumption of British consumers, as well as with findings by Harland et al. [44] regarding pro-environmental behavior such as reduced meat consumption of Dutch citizens. 
Behavioral control-related elements proved to be insignificant in our model. A theory-based interpretation of a low impact of control-related aspects may indicate an overall perceived high personal control over behavior [39]. This interpretation may be supported by the descriptive analysis of our initial indicator system for perceived behavioral control, where the means of the three indicators are all above 4.5 on a scale from 1 (low personal control) to 7 (high personal control) with little variance. Considering next the construct of subjective norms, a low relevance may indicate little influence of others for the eating behavior in the canteen. This, however, stands against numerous studies which find that social modeling is an important aspect of eating behavior when seated with others [68-71]. One explanation for the low relevance of subjective norms in our model may be derived from the results of the study of Hermans et al. [70]. They manipulated an eating situation by the amount of food that was consumed by a companion. Although different consumption of a companion (small, standard and large portion) influenced food consumption of young women significantly, there were no differences in perceived amount of food consumption by the respective women. Hence, it may be assumed that social influences on eating and leftover behavior to a certain extent are unconscious. The findings of Miao and Wei [72] that sustainable consumer behaviors in out-of-home settings are generally less influenced by social factors than they are at home might be another explanation. Besides, the most significant relevant others influencing throw away behavior mentioned in our pre-study were (grand) parents and media using pictures of starving people. These influences were definitely not very prominent in our setting. An additional reason for our results may be that subjective norms in our model were measured by canteen guests' general perceptions of "relevant others" and not related to people who are seated in the canteen and by "disposing food" and not by "leaving food on the plate". Accordingly, a low level of compatibility for measuring subjective norms with the specific setting analyzed may account for weak model relationships.

The strong relevance of personal norms and attitudes in our model supports similar findings for reduced meat consumption [44] and household recycling behavior [37]. Accordingly, Barr [51] notes that environmental behavior may be described as strongly intrinsically motivated. For households' waste-reduction behavior, he finds that personal values have a direct as well as indirect influence on behavioral intention and actual behavior. With respect to claims that food waste in service facilities may well depend on personal factors of consumers the establishment of knowledge and awareness is a relevant factor to decrease food waste [30,72]. Our study supports the relevance of personal factors and hence their potential to decrease food waste.

However, related to actual leftover behavior, we find that intention alone can only explain a share of leftover behavior and hence should be complemented by situational measures. The considered situational variable, perceived taste of food, had a significant direct impact on plate leftovers. This result is in line with findings from Harnack et al. [73] that taste is the most important criterion for choosing food in different settings and from WRAP [74] for school canteens, where disliking food is an important reason for plate leftovers. Moreover, it may be interpreted as support for the link between food waste and consumer satisfaction [25] and hence also stresses the relevance of food service design in order to influence food waste from guests.

Overall, our model provides sufficient fit to data and reaches a good $\mathrm{R}^{2}$ for behavioral intention, as well as a satisfactory $\mathrm{R}^{2}$ for leftover behavior. Nevertheless, future research may consider additional determinants besides behavioral intention and the situational variable perceived taste, to model plate leftover behavior. In this respect, the inclusion of consumer's food choice seems relevant as the manipulation of choice behavior has proven to influence plate leftovers [75]. Moreover, assuming that both, food choice and eating behavior, may be determined to a relevant extent by situational factors [76] additional situational variables such as time pressure or portion size may improve the understanding of actual leftover behavior.

In line with other empirical studies, the present one is subject to different limitations. Those partly stem from constraints regarding the collected data. In this respect, two of the behavioral constructs (subjective norms and behavioral intention) in our measurement system were covered by only two 
indicators, respectively. In addition, subjective norm was determined in a rather general way and neither specific to plate leftovers nor to the people in the canteen. Besides a limitation of our research is that applied measurement systems relate to three different formulations of leftover behavior: wasting food in the cafeteria, eating everything up (clearing the plate), and leaving food on the plate. Although the overall model fit and the significant estimates indicate the comparability of all three formulations, a better aligned measurement might have led to better estimation results.

Finally, the measurement of actual plate leftover behavior was conducted only for one specific day and by self-disclosure. Regarding the former, leftover behavior (food choice and eating) on one specific day may be assumed to be significantly influenced by external and situational factors [76]. In our model, we only considered taste as single situational determinant. Regarding the latter, self-reported information on plate leftovers may be subject to social desirability bias since the topic of food waste is related to moral and ethical considerations, as is revealed by the strong impact of personal norms in our model. Since reducing food waste can also be seen as a means to increase sustainability, the findings of Klaiman et al. [77] on purchases of green goods gain importance. Klaiman et al. [77] designed a study displaying the presence of the social desirability bias coming along with direct questions regarding self-reported green purchases. Hence, future studies should reduce the effects of the social desirability bias by using, e.g., observational data displaying the amount of food served and the amount of leftovers, respectively, per person to link it with the other individual data or indirect questioning such as asking participants to answer questions from the perspective of another individual or group. These approaches are also not without limitations as e.g., observation of food choice and leftover behavior might attract consumers' attention. Besides, such a procedure has to be accepted by e.g., the staff committee which was not possible in our case. The social desirability bias becomes even more important since, in the last five years, after the data collection of this study in 2012, not-for-profits, governments and media in many European countries, including Germany, have addressed different elements of food waste to raise consumers' awareness for the pertinence of the topic. Hence, the environment in which consumers make their food choice decisions today is different which might result in even higher relevance of personal attitudes for leftovers and occurrence of social desirability bias than found in our study.

\section{Conclusions}

The aim of the presented study was to derive and empirically test a behavioral model to gain better understanding of individual food leftover behavior in a company catering facility. Being aware of the fact that the whole chain concerned with the production of food is responsible for the impacts of their economic activities on sustainability [6], see, e.g., Coggins' [78] plea for shared responsibility for waste prevention, this paper focuses on the behavior of consumers. Based on the TPB and the additionally considered constructs personal norms and the situational measure of perceived taste of food, a structural equation model was estimated for a sample of 158 German canteen guests. The results indicate a good model fit for the defined latent behavioral constructs as well as for the overall structural model. Our estimation results suggest that food leftover behavior in general is determined by both situational variables as well as behavioral determinants. Behavioral intention with respect to food leftover behavior appears to be greatly determined by personal norms and attitudes of an individual, whereas behavioral determinants that are related to perception of other people (subjective norms) and of the environment (perceived behavioral control) appear less relevant. Regarding situational factors, perceived taste of food plays an important role for leaving food on the plate.

Overall, our study shows that, to determine individual food leftover behavior in a canteen setting, determinants derived from behavioral theories such as the TPB should be complemented by situational variables. Therefore, our study supports the relevance of environmental factors and hence recommends that, to reduce leftovers in out-of-home settings, the design of service systems should consider existing recommendations on portion sizes, service styles and menu designs. However, our study also clearly states that influences from environmental factors on plate leftovers are complemented 
by personal or individual factors. Consequently, interventions to reduce leftovers should also target these aspects of consumers, e.g., by raising problem awareness or personal feelings of responsibility. Regarding future research, it may be of great importance to consider leftover behavior not only by self-reported information but also to include individual food choices and related food leftovers by objective measures in order to improve the validity of results. Finally, additional empirical testing of the model in different canteen settings may be applied to derive relevant situational factors for food leftovers (such as perceived portion size and perceived taste of food) at a more general level. The aim of such research would be to gain more general estimates about the relative importance of specific situational, food-service related aspects and personal aspects and to accordingly provide more general recommendations on initiatives for reducing plate leftovers.

Acknowledgments: We acknowledge support by the German Research Foundation and the Open Access Publication Funds of Technische Universität Berlin.

Author Contributions: This paper was written in cooperation between Bettina Lorenz, Nina Langen, and Monika Hartmann with support of Stefan Hirsch. The quantitative analyses were mainly carried out by Bettina Lorenz, Nina Langen and Stefan Hirsch and based on preliminary analyses of Olga Kanz. The empirical design for data collection was developed by Olga Kanz (née Finkbeiner), Nina Langen and Monika Hartmann. Olga Kanz (née Finkbeiner) was responsible for the data collection and clearing of data. All authors made substantive intellectual contributions to the scientific content and approved the final manuscript.

Conflicts of Interest: This research did not receive any specific grant from funding agencies in the public, commercial, or not-for-profit sectors.

\section{Appendix A}

Table A1. Descriptive Statistics for Measured Variables.

\begin{tabular}{ccccccccc}
\hline Variable & Sample Size & Mean & Variance & Skewness & Kurtosis & Min & Max & Median \\
\hline Intention_1 & 156 & 5.65 & 2.92 & -1.51 & 1.27 & 1 & 7 & 6 \\
Intention_2 & 156 & 5.44 & 2.84 & -1.00 & -0.01 & 1 & 7 & 6 \\
Attitude_1 & 156 & 5.90 & 1.94 & -1.54 & 2.13 & 1 & 7 & 6 \\
Attitude_2 & 156 & 5.42 & 2.49 & -0.85 & -0.23 & 1 & 7 & 6 \\
Attitude_3 & 156 & 4.99 & 2.81 & -0.53 & -0.61 & 1 & 7 & 5 \\
Attitude_4 & 155 & 5.03 & 2.66 & -0.57 & -0.49 & 1 & 7 & 5 \\
Subj. Norm_1 & 156 & 5.51 & 2.14 & -1.12 & 0.57 & 1 & 7 & 6 \\
Subj. Norm_2 & 147 & 5.46 & 1.92 & -1.14 & 1.03 & 1 & 7 & 6 \\
Pers. Norm_1 & 152 & 5.51 & 2.51 & -1.10 & 0.57 & 1 & 7 & 6 \\
Pers. Norm_2 & 154 & 6.09 & 1.52 & -1.77 & 3.55 & 1 & 7 & 7 \\
Pers. Norm_3 & 156 & 6.29 & 1.41 & -2.59 & 7.65 & 1 & 7 & 7 \\
Leftovers & 156 & 0.42 & 0.56 & 1.79 & 2.38 & 0 & 3 & 0 \\
Factor_1 & 156 & 0.00 & 0.94 & 0.64 & -0.34 & -1.26 & 2.60 & \\
Factor_2 & 156 & 0.00 & 0.94 & 1.18 & 0.56 & -0.85 & 3.09 & \\
Factor_3 & 156 & 0.00 & 0.93 & 0.24 & -0.48 & -1.49 & 2.60 & \\
Factor_4 & 156 & 0.00 & 0.95 & 0.09 & -0.82 & -1.77 & 1.88 & \\
Taste & 156 & 5.58 & 0.72 & -0.72 & 0.82 & 3 & 7 & 6 \\
\hline
\end{tabular}


Table A2. Correlation Matrix for Measured Variables.

\begin{tabular}{|c|c|c|c|c|c|c|c|c|c|c|c|c|c|c|c|c|c|}
\hline & I_1 & I_2 & A_1 & A_2 & A_3 & A_ 4 & SN_1 & SN_2 & PN_1 & PN_2 & PN_3 & LO & F 1 & F 2 & F 3 & F4 & Taste \\
\hline Intention_1 & 1.000 & & & & & & & & & & & & & & & & \\
\hline Intention_2 & 0.413 & 1.000 & & & & & & & & & & & & & & & \\
\hline Attitude_1 & 0.195 & 0.355 & 1.000 & & & & & & & & & & & & & & \\
\hline Attitude_2 & 0.140 & 0.322 & 0.732 & 1.000 & & & & & & & & & & & & & \\
\hline Attitude_3 & 0.183 & 0.192 & 0.565 & 0.633 & 1.000 & & & & & & & & & & & & \\
\hline Attitude_4 & 0.158 & 0.333 & 0.556 & 0.726 & 0.604 & 1.000 & & & & & & & & & & & \\
\hline Subj. Norm_1 & 0.042 & 0.166 & -0.044 & 0.041 & -0.025 & -0.011 & 1.000 & & & & & & & & & & \\
\hline Subj. Norm_2 & 0.148 & 0.197 & 0.088 & 0.032 & -0.017 & -0.007 & 0.744 & 1.000 & & & & & & & & & \\
\hline Pers. Norm_1 & 0.110 & 0.226 & 0.313 & 0.288 & 0.195 & 0.176 & 0.107 & 0.122 & 1.000 & & & & & & & & \\
\hline Pers. Norm_2 & 0.280 & 0.454 & 0.338 & 0.269 & 0.151 & 0.314 & 0.144 & 0.164 & 0.439 & 1.000 & & & & & & & \\
\hline Pers. Norm_3 & 0.226 & 0.283 & 0.185 & 0.120 & 0.017 & 0.142 & 0.093 & 0.140 & 0.415 & 0.669 & 1.000 & & & & & & \\
\hline Leftovers & -0.247 & -0.128 & 0.010 & 0.079 & 0.022 & 0.017 & -0.128 & -0.110 & -0.131 & -0.185 & -0.264 & 1.000 & & & & & \\
\hline Factor_1 & -0.093 & -0.070 & 0.039 & -0.030 & 0.041 & 0.025 & -0.086 & -0.143 & 0.040 & 0.006 & -0.052 & 0.045 & 1.000 & & & & \\
\hline Factor_2 & -0.136 & -0.103 & -0.070 & -0.056 & -0.051 & -0.050 & -0.003 & -0.037 & 0.040 & -0.048 & -0.128 & 0.167 & 0.293 & 1.000 & & & \\
\hline Factor_3 & -0.194 & -0.114 & -0.118 & -0.158 & -0.116 & -0.118 & -0.085 & -0.068 & -0.081 & -0.188 & -0.092 & 0.143 & 0.119 & 0.347 & 1.000 & & \\
\hline Factor_4 & 0.009 & -0.085 & 0.002 & -0.052 & 0.020 & 0.019 & 0.090 & 0.121 & 0.087 & 0.020 & -0.041 & 0.017 & 0.425 & 0.081 & -0.108 & 1.000 & \\
\hline Taste & 0.067 & 0.048 & -0.156 & -0.077 & -0.020 & -0.047 & 0.075 & 0.110 & -0.011 & 0.038 & 0.115 & -0.337 & -0.174 & 0.061 & 0.136 & -0.137 & 1.000 \\
\hline
\end{tabular}


Table A3. Confirmatory Factor Analysis Results.

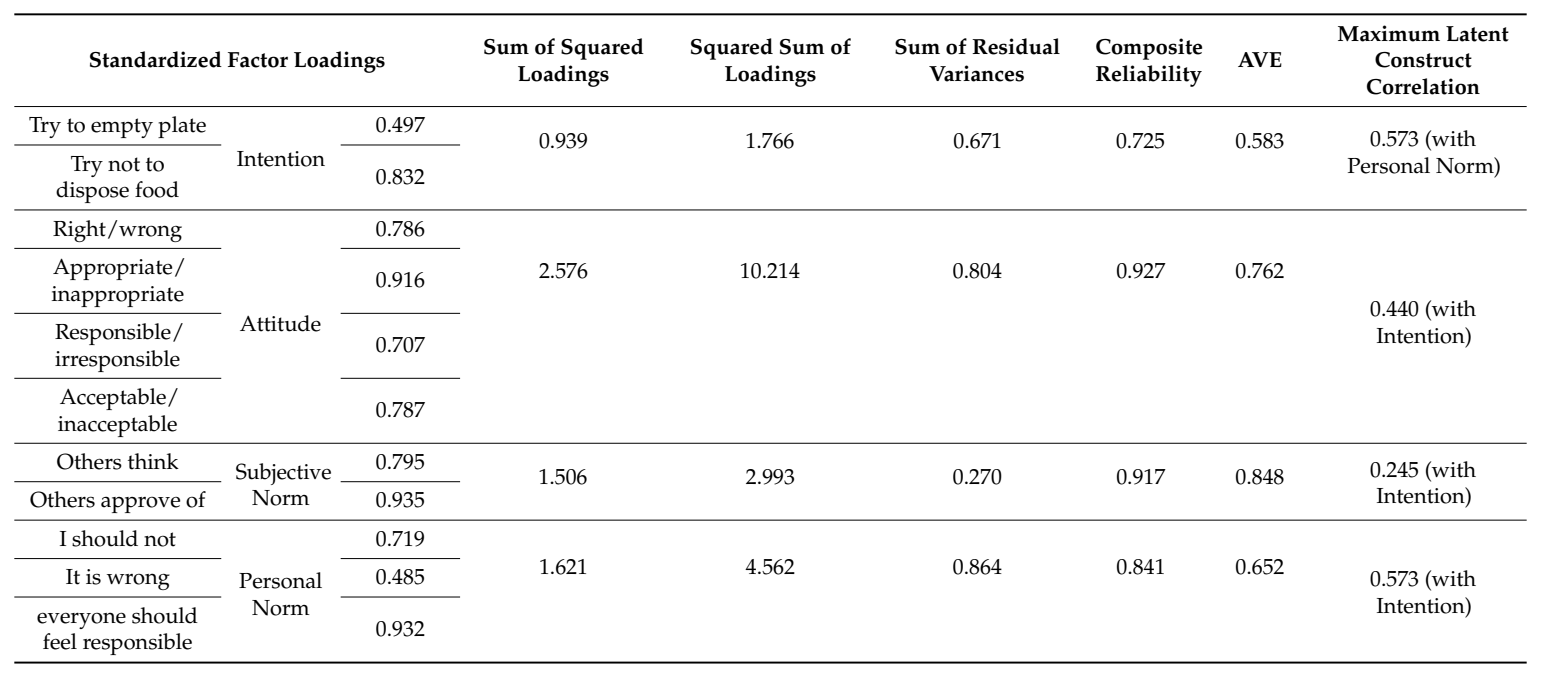

Table A4. Modification Indices (M.I.) for structural model.

\begin{tabular}{|c|c|c|c|c|c|c|}
\hline \multicolumn{3}{|c|}{ Cutoff-Value at Significance Level $\alpha=0.05: 3.84$} & M.I. & E.P.C. & Std E.P.C. & StdYX E.P.C. \\
\hline \multicolumn{7}{|c|}{ BY Statements } \\
\hline Intention & BY & Attitude_1 & 4.398 & 0.243 & 0.221 & 0.158 \\
\hline Attitudes & BY & Pers. Norm_2 & 4.328 & 0.253 & 0.277 & 0.173 \\
\hline Attitudes & BY & Pers. Norm_1 & 4.507 & -0.169 & -0.185 & -0.156 \\
\hline Pers. Norms & $\mathrm{BY}$ & Attitude_1 & 4.463 & 0.236 & 0.185 & 0.133 \\
\hline \multicolumn{7}{|c|}{ ON/BY Statements } \\
\hline Leftover & ON & Attitudes & 3.903 & 0.125 & 0.137 & 0.183 \\
\hline \multicolumn{7}{|c|}{ ON Statements } \\
\hline Attitudes & $\mathrm{ON}$ & Leftovers & 6.186 & 0.318 & 0.291 & 0.217 \\
\hline Pers. Norms & ON & Factor 3 & 4.643 & -0.147 & -0.188 & -0.181 \\
\hline Leftovers & ON & Factor 2 & 4.104 & 0.119 & 0.119 & 0.153 \\
\hline \multicolumn{7}{|c|}{ WITH Statements } \\
\hline Attitude_4 & WITH & Attitude_1 & 8.847 & -0.311 & -0.311 & -0.36 \\
\hline Subj. Norm_1 & WITH & Attitude_1 & 9.165 & -0.225 & -0.225 & -0.284 \\
\hline Subj. Norm_2 & WITH & Attitude_1 & 7.092 & 0.187 & 0.187 & 0.541 \\
\hline Pers. Norm_2 & WITH & Attitude_4 & 4.015 & -0.254 & -0.254 & -0.18 \\
\hline Pers. Norm_3 & WITH & Pers. Norm_2 & 4.562 & -0.366 & -0.366 & -0.554 \\
\hline Leftovers & WITH & Attitudes & 4.727 & 0.14 & 0.136 & 0.198 \\
\hline Factor 1 & WITH & Subj. Norms & 6.476 & -0.201 & -0.177 & -0.182 \\
\hline Factor 3 & WITH & Pers. Norms & 4.437 & -0.124 & -0.158 & -0.164 \\
\hline Factor 4 & WITH & Subj. Norms & 5.726 & 0.196 & 0.172 & 0.177 \\
\hline Taste & WITH & Factor 1 & 4.208 & -0.117 & -0.117 & -0.142 \\
\hline
\end{tabular}

\section{References}

1. Gustavsson, J.; Cederberg, C.; Sonesson, U.; van Otterdijk, R.; Meybeck, A. Global Food Losses and Food Waste; FAO: Rome, Italy, 2011.

2. Beretta, C.; Stoessel, F.; Baier, U.; Hellweg, S. Quantifying food losses and the potential for reduction in Switzerland. Waste Manag. 2013, 33, 764-773. [CrossRef] [PubMed]

3. FAO. Food Wastage Footprint_Impacts on Natural Resources; FAO: Rome, Italy, 2013. Available online: http:/ / www.fao.org/docrep/018/i3347e/i3347e.pdf (accessed on 9 May 2017). 
4. Pretty, J.N.; Ball, A.S.; Lang, T.; Morison, J.I.L. Farm costs and food miles: An assessment of the full cost of the UK weekly food basket. Food Policy 2005, 30, 1-19. [CrossRef]

5. Searchinger, T.; Hanson, C.; Ranganathan, J.; Lipinski, B.; Waite, R.; Winterbottom, R.; Dinshaw, A.; Heimlich, R. Creating a Sustainable Food Future; World Resources Intitute: Washington, DC, USA, 2013.

6. Göbel, C.; Langen, N.; Blumenthal, A.; Teitscheid, P.; Ritter, G. Cutting Food Waste through Cooperation along the Food Supply Chain. Sustainability 2015, 7, 1429-1445. [CrossRef]

7. Halloran, A.; Clement, J.; Kornum, N.; Bucatariu, C.; Magid, J. Addressing food waste reduction in Denmark. Food Policy 2014, 49, 294-301. [CrossRef]

8. Monier, V.; Mudgar, S.; Escalon, V.; O’Connor, C.; Gibon, T.; Anderson, G.; Montoux, H. Preparatory Study on Food Waste across EU 27; European Commission: Brussels, Belgium, 2010; Volume 54.

9. Stenmarck, A.; Jensen, C.; Quested, T.; Moates, G. Estimates of European Food Waste Levels. 2016. Available online: https://www.eu-fusions.org/phocadownload/Publications/Estimates\%20of\% 20European\%20food\%20waste\%20levels.pdf (accessed on 10 April 2017).

10. Langen, N.; Sahinol, M. Mysterious numbers in the German discussion of household food waste. In Vordenken-Mitdenken-Nachdenken. Technologiefolgenabschätzung im Dienst einer Pluralistischen Politik; Bellucci, S., Bröchler, S., Decker, M., Nentwich, M., Rey, L., Sotoudeh, M., Eds.; Edition Sigma: Berlin, Germany, 2015.

11. Langen, N.; Burdick, B. Befragung von Privathaushalten durch die Verbraucherzentrale Nordrhein-Westfalen. In Verringerung von Lebensmittelabfällen-Identifiaktion von Ursachen und Handlungsoptionen in Nordrhein-Westfalen; Göbel, C., Teitscheid, P., Ritter, G., Blumenthal, A., Friedric, S., Frick, T., Grostollen, L., Möllenbeck, C., Rottstegge, L., Pfeiffer, C., et al., Eds.; Fachhochschule Münster: Münster, Germany, 2012; pp. 61-82.

12. Evans, D. Beyond the Throwaway Society: Ordinary Domestic Practice and a Sociological Approach to Household Food Waste. Sociology 2011, 46, 41-56. [CrossRef]

13. Quested, T.E.; Marsh, E.; Stunell, D.; Parry, A.D. Spaghetti soup: The Complex World of Food Waste Behaviours. Resour. Conserv. Recycl. 2013, 79, 43-51. [CrossRef]

14. Redman, E.; Redman, A. Transforming Sustainable Food and Waste Behaviors by Realigning Domains of Knowledge in Our Education System. J. Clean. Prod. 2014, 64, 147-157. [CrossRef]

15. Quested, T.; Ingle, R.; Parry, A. Household Food and Drink Waste in the United Kingdom 2012; WRAP: Banbury, UK, 2013.

16. Van Boxstael, S.; Devlieghere, F.; Berkvens, D.; Vermeulen, A.; Uyttendaele, M. Understanding and Attitude Regarding the Shelf Life Labels and Dates on Pre-Packed Food Products by Belgian Consumers. Food Control 2014, 37, 85-92. [CrossRef]

17. Ganglbauer, E.; Fitzpatrick, G.; Subasi, Ö.; Güldenpfennig, F. Think Globally, Act Locally: A Case Study of a Free Food Sharing Community and Social Networking. In Proceedings of the 17th ACM conference on Computer Supported Cooperative Work \& Social Computing, Baltimore, MD, USA, 15-19 February 2014; pp. 911-921.

18. Young, W.; Russell, S.V.; Robinson, C.A.; Barkemeyer, R. Can Social Media Be a Tool for Reducing Consumers' Food Waste? A Behaviour Change Experiment by a UK Retailer. Resour. Conserv. Recycl. 2016, 117, 9. [CrossRef]

19. Varjonen, J.; Peltoniemi, A. Eating out as an Aspect of Changes in Eating Habits 1990-2010; National Consumer Research Centre: Helsinki, Finland, 2012.

20. Falasconi, L.; Vittuari, M.; Politano, A.; Segrè, A. Food Waste in School Catering: An Italian Case Study. Sustainability 2015, 7, 14745-14760. [CrossRef]

21. Bond, M.; Meacham, T.; Bhunnoo, R.; Benton, T.G. Food Waste Within Global Food Systems; Global Food Security Programme: Swindon, UK, 2013.

22. Katajajuuri, J.M.; Silvennoinen, K.; Hartikainen, H.; Heikkilä, L.; Reinikainen, A. Food Waste in the Finnish Food Chain. J. Clean. Prod. 2014, 73, 322-329. [CrossRef]

23. Silvennoinen, K.; Katajajuuri, J.M.; Hartikainen, H.; Jalkanen, L.; Koivupuro, H.K.; Reinikainen, A. Food Waste Volume and Compositon in the Finnish Supply Chain: Special Focus on Food Service Sector. In Proceedings of the Fourth International Symposium on Energy from Biomass and Waste, Venice, Italy, 12-15 November 2012; International Waste Working Group: Venice, Italy, 2012. 
24. Speck, M.; Göbel, C.; Schweissinger, J.; Teitscheid, P.; Rohn, H.; Langen, N. Nachhaltigkeit in der Gemeinschaftsverpflegung-Das Forschungsprojekt NAHGAST. Hauswirtsch. Wiss. 2016, 2, 86-92.

25. Ferreira, M.; Martins, M.L.; Rocha, A. Food Waste as an Index of Foodservice Quality. Br. Food J. 2013, 115, 1628-1637. [CrossRef]

26. Aschemann-Witzel, J.; Maroscheck, N.; Hamm, U. Are Organic Consumers Preferring or Avoiding Foods with Nutrition and Health Claims? Food Qual. Preference 2013, 30, 68-76. [CrossRef]

27. Dinis, D.; Martins, M.L.; Rocha, A. Plate Waste as an Indicator of Portions Inadequacy at School Lunch. Int. J. Biol. Biomol. Agric. Food Biotechnol. Eng. 2013, 7, 187-190.

28. Sanchez, A.; Contreras, L.R. Relationship of the Physical Dining Environment and Service Styles to Plate Waste in Middle/Junior High Schools; National Food Service Management Institute: Starkville, MS, USA, 2003.

29. Kim, E.; Ham, S.; Yang, I.S.; Choi, J.G. The Roles of Attitude, Subjective Norm, and Perceived Behavioral Control in the Formation of Consumers' Behavioral Intentions to Read Menu Labels in the Restaurant Industry. Int. J. Hosp. Manag. 2013, 35, 203-213. [CrossRef]

30. Casimir, J. Food Waste at the School Level; Uppsala University: Uppsala, Sweden, 2014.

31. BVE. Rekordumsätze im Deutschen Außer-Haus-Markt. Available online: http://www.bve-online.de/ presse/bve-aktuell/aktuell-160422/aktuell-160422-001-ausser-haus-markt (accessed on 4 May 2017).

32. French, S.; Stables, G. Environmental Interventions to Promote Vegetable and Fruit Consumption among Youth in School Settings. Prev. Med. 2003, 37, 593-610. [CrossRef] [PubMed]

33. Eberle, U.; Hayn, D. Ernährungswende: Eine Herausforderung für Politik, Unternehmen und Gesellschaft; Öko-Institut e.V. und Institut für sozial-öklogische Forschung: Freiburg, Germany, 2007.

34. Fakih, K.; Assaker, G.; Assaf, A.G.; Hallak, R. Does Restaurant Menu Information Affect Customer Attitudes and Behavioral Intentions? A Cross-Segment Empirical Analysis Using PLS-SEM. Int. J. Hosp. Manag. 2016, 57, 71-83. [CrossRef]

35. Stancu, V.; Haugaard, P.; Lähteenmäki, L. Determinants of Consumer Food Waste Behaviour: Two Routes to Food Waste. Appetite 2016, 96, 7-17. [CrossRef] [PubMed]

36. Tonglet, M.; Phillips, P.S.; Read, A.D. Using the theory of planned behaviour to investigate the determinants of recycling behaviour: a case study from Brixworth, UK. Resour. Conserv. Recyl. 2004, 41, 191-214. [CrossRef]

37. Yazdanpanah, M.; Forouzani, M. Application of the theory of planned behaviour to predict Iranian students' intention to purchase organic food. J. Clean. Prod. 2015, 107, 342-352. [CrossRef]

38. Lorenz, B.A.-S.; Hartmann, M.; Langen, N. What Makes People Leave Their Food? The Interaction of Personal and Situational Factors Leading to Plate Leftovers in Canteens. Appetite 2017, 116, 45-56. [CrossRef] [PubMed]

39. Ajzen, I. The theory of planned behavior. Organ. Behav. Hum. Decis. Process. 1991, 50, 179-211. [CrossRef]

40. Ajzen, I.; Fishbein, M. The influence of Attitudes on Behavior. In The Handbook of Attitudes; Albarracin, D., Johnson, B.T., Zanna, M.P., Eds.; Psychology Press: New York, NY, USA, 2005; pp. 173-221.

41. Armitage, C.J.; Conner, M. Efficacy of the Theory of Planned Behaviour: A Meta-Analytic Review. Br. J. Soc. Psychol. 2001, 40, 471-499. [CrossRef] [PubMed]

42. Tarkiainen, A.; Sundqvist, S. Subjective Norms, Attitudes And Intentions of Finnish Consumers in Buying Organic Food. Br. Food J. 2005, 107, 808-822. [CrossRef]

43. Mahon, D.; Cowan, C.; McCarthy, M. The Role of Attitudes, Subjective Norm, Perceived Control and Habit in the Consumption of Ready Meals and Takeaways in Great Britain. Food Qual. Preference 2006, 17, 474-481. [CrossRef]

44. Harland, P.; Staats, H.; Wilke, H.A.M. Explaining Proenvironmental Intention and Behavior by Personal Norms and the Theory of Planned Behavior. J. Appl. Soc. Psychol. 1999, 29, 2505-2528. [CrossRef]

45. Vermeir, I.; Verbeke, W. Sustainable Food Consumption among Young Adults in Belgium: Theory of Planned Behaviour and the Role of Confidence and Values. Ecol. Econ. 2008, 64, 542-553. [CrossRef]

46. Cook, A.J.; Kerr, G.N.; Moore, K. Attitudes And Intentions towards Purchasing GM Food. J. Econ. Psychol. 2002, 23, 557-572. [CrossRef]

47. Davies, J.; Foxall, G.R.; Pallister, J.G. Beyond the Intention-Behaviour Mythology: An Integrated Model of Recycling. Mark. Theory 2002, 2, 21-113. [CrossRef]

48. Schwartz, S.H. Normative Influences On Alturism. Adv. Exp. Soc. Psychol. 1977, 10, 221-279. 
49. Milfont, T.L.; Sibley, C.G.; Duckitt, J. Testing the Moderating Role of the Components of Norm Activation on the Relationship between Values and Environmental Behavior. J. Cross. Cult. Psychol. 2010, 41, 124-131. [CrossRef]

50. Arvola, A.; Vassallo, M.; Dean, M.; Lampila, P.; Saba, A.; Lähteenmäki, L.; Shepherd, R. Predicting Intentions to Purchase Organic Food: The Role of Affective and Moral Attitudes in the Theory of Planned Behaviour. Appetite 2008, 50, 443-454. [CrossRef] [PubMed]

51. Barr, S. Factors Influencing Environmental Attitudes and Behaviors: A U.K. Case Study of Household Waste Management. Environ. Behav. 2007, 39, 435-473. [CrossRef]

52. Graham-Rowe, E.; Jessop, D.C.; Sparks, P. Identifying Motivations and Barriers to Minimising Household Food Waste. Resour. Conserv. Recycl. 2014, 84, 15-23. [CrossRef]

53. Aertsens, J.; Verbeke, W.; Mondelaers, K.; van Huylenbroeck, G. Personal Determinants of Organic Food Consumption: A Review. Br. Food J. 2009, 111, 1140-1167. [CrossRef]

54. Carrington, M.J.; Neville, B.A.; Whitwell, G.J. Why Ethical Consumers Don't Walk Their Talk: Towards a Framework for Understanding the Gap between the Ethical Purchase Intentions and Actual Buying Behaviour of Ethically Minded Consumers. J. Bus. Ethics 2010, 97, 139-158. [CrossRef]

55. Tonglet, M.; Phillips, P.S.; Bates, M.P. Determining the Drivers for Householder Pro-Environmental Behaviour: Waste Minimisation Compared to Recycling. Resour. Conserv. Recyl. 2004, 42, 27-48. [CrossRef]

56. Göbel, C.; Blumenthal, A.; Niepagenkemper, L.; Baumkoetter, D.; Teitscheid, P.; Wetter, C. Bericht zum Forschungs- und Entwicklungsprojekt "Reduktion von Warenverlusten und Warenvernichtung in der AHV-Ein Beitrag zur Steigerung der Ressourceneffizienz" November 2014; Institut für Nachhaltige Ernährung und Ernährungswirtschaft Fachhochschule Muenster (iSuN): Muenster, Germany, 2014.

57. Cohen, J.F.W.; Richardson, S.A.; Cluggish, S.A.; Parker, E.; Catalano, P.J.; Rimm, E.B. Effects of Choice Architecture and Chef-Enhanced Meals on the Selection and Consumption of Healthier School Foods. JAMA Pediatr. 2015, 169, 431-437. [CrossRef] [PubMed]

58. Finkbeiner, O. Lebensmittelabfälle in der Betriebsverpflegung-Erfassung von Mengen und Ursachen; AVM: München, Germany, 2013.

59. Ajzen, I. Constructing a TPB Questionnaire: Conceptual and Methodological Considerations. Time 2006, $2002,1-13$.

60. Göbel, C.; Teitscheid, P.; Ritter, G.; Blumenthal, A.; Friedric, S.; Frick, T.; Grostollen, L.; Möllenbeck, C.; Rottstegge, L.; Pfeiffer, C.; et al. Verringerung von Lebensmittelabfällen-Identifikation von Ursachen und Handlungsoptionen in Nordrhein-Westfalen; Fachhochschule Münster-Institut für Nachhaltige Ernährung und Ernährungswissenschaft (iSuN): Münster, Germany, 2012.

61. Manstead, A.S.R.; Parker, D. Evaluating and Extending the Theory of Planned Behaviour. Eur. Rev. Soc. Psychol. 1995, 6, 69-95. [CrossRef]

62. Rhemtulla, M.; Brosseau-Liard, P.É.; Savalei, V. When Can Categorical Variables Be Treated as Continuous? A Comparison of Robust Continuous and Categorical Sem Estimation Methods under Suboptimal Conditions. Psychol. Methods 2012, 17, 354-373. [CrossRef] [PubMed]

63. Destatis. Statistisches Jahrbuch Deutschland und Internationales; Destatis: Wiesbaden, Germany, 2015.

64. Diekmann, A.; Preisendörfer, P. Green and Greenback. Ration. Soc. 2003, 15, 441-472. [CrossRef]

65. Bagozzi, R.P.; Yi, Y. On the Evaluation of Structural Equation Models. J. Acad. Mark. Sci. 1988, 16, 74-94. [CrossRef]

66. Fornell, C.; Larcker, D.F. Evaluating Structural Equation Models with Unobservable Variables and Measurement Error. J. Mark. Res. 1981, 18, 39-50. [CrossRef]

67. Blunch, N.J. Introduction to Structural Equation Modelling Using SPSS and AMOS; SAGE Publications Ltd.: London, UK, 2008.

68. Clendenen, V.I.; Herman, C.P.; Polivy, J. Social Facilitation of Eating among Friends and Strangers. Appetite 1994, 23, 1-13. [CrossRef] [PubMed]

69. Cruwys, T.; Bevelander, K.E.; Hermans, R.C.J. Social modeling of eating: A review of when and why social influence affects food intake and choice. Appetite 2015, 86, 3-18. [CrossRef] [PubMed]

70. Hermans, R.C.J.; Larsen, J.K.; Peter Herman, C.; Engels, R.C.M.E. How much should I eat? Situational norms affect young women's food intake during meal time. Br. J. Nutr. 2012, 107, 588-594. [CrossRef] [PubMed]

71. Pliner, P.; Chaiken, S. Eating, Social Motives, and Self-Presentation in Women and Men. J. Exp. Soc. Psychol. 1990, 26, 240-254. [CrossRef] 
72. Miao, L.; Wei, W. Consumers' pro-environmental behavior and the underlying motivations: A comparison between household and hotel settings. Int. J. Hosp. Manag. 2013, 32, 103-112. [CrossRef]

73. Harnack, L.J.; French, S.A.; Oakes, J.M.; Story, M.T.; Jeffery, R.W.; Rydell, S.A. Effects of calorie labeling and value size pricing on fast food meal choices: results from an experimental trial. Int. J. Behav. Nutr. Phys. Act. 2008, 5, 63. [CrossRef] [PubMed]

74. WRAP. Food Waste in Schools; WRAP: Banbury, UK, 2011.

75. Kallbekken, S.; Sælen, H. Nudging hotel guests to reduce food waste as a win-win environmental measure. Econ. Lett. 2013, 119, 325-327. [CrossRef]

76. Wansink, B. Environmental factors that increase the food intake and consumption volume of unknowing consumers. Annu. Rev. Nutr. 2004, 24, 455-479. [CrossRef] [PubMed]

77. Klaiman, K.; Ortega, D.L.; Garanache, C. Consumer Preferences and Demand for Packaging Material and Recycability. Resour. Conserv. Recycl. 2016, 115, 1-8. [CrossRef]

78. Coggins, C. Waste prevention-An issue of shared responsibility for UK producers and consumers: Policy options and measurement. Resour. Conserv. Recycl. 2001, 32, 181-190. [CrossRef]

(C) 2017 by the authors. Licensee MDPI, Basel, Switzerland. This article is an open access article distributed under the terms and conditions of the Creative Commons Attribution (CC BY) license (http:/ / creativecommons.org/licenses/by/4.0/). 